Revista Iberoamericana, Vol. LXVIII, Núm. 198, Enero-Marzo 2002, 91-105

\title{
CADÁVERES EXQUISITOS: COLECCIONES Y COLONIALISMO EN NOTICIAS DEL IMPERIO
}

\author{
POR \\ KRISTINE IBSEN \\ University of Notre Dame
}

“Otro día/ veremos la resurrección de las mariposas

Aunque el factor dominante del interés francés en México haya sido político (Betts 48-9), comunicados oficiales de la prensa francesa así como varios libros publicados inmediatamente antes y durante la intervención (1861-1867) insistían en las riquezas materiales del país, prometiendo ganancias espectaculares para quien controlara el gobierno (véanse Chevalier, cit. Belinkii 61-62, Micard 156-57, Baril 174). Hasta el mismo Napoleón III reconoció los apuntalamientos económicos de la empresa: “En el estado actual de la civilización del mundo, la prosperidad de la América no es indiferente a la Europa porque es la que alimenta nuestras fábricas y hace vivir nuestro comercio" (cit. Bouzet 12-13). La intervención francesa también coincidió con un creciente interés por los artefactos prehispánicos y el coleccionismo en general. La primera exposición importante de piezas hispanoamericanas en Europa se había presentado en el Louvre apenas diez años antes y, durante la ocupación militar, estudiosos franceses emprendieron excavaciones a gran escala de los yacimientos arqueológicos de México, enviando una infinidad de objetos a Francia para engrosar colecciones tanto públicas como privadas. Con el fracaso de la expedición, disminuyó el breve devaneo europeo con el arte precolombino y las piezas fueron trasladadas al museo Trocadero, donde años después las visitarían artistas surrealistas y otros seguidores del movimiento primitivista (Williams 149-156). Como sugiere este ejemplo, la historia del coleccionismo es fundamental para nuestra comprensión de la manera en que ciertos grupos sociales han podido apropiarse de lo "exótico" sin reconocer las relaciones de poder responsables de la adquisición de los objetos. Es más, James Clifford sugiere que podemos comparar el acto de coleccionar con el de la narración histórica en la medida en que el uso del pasado se convierte en una acumulación, clasificada de acuerdo con la jerarquía del coleccionista/historiador (274). Esta situación se refleja en la apropiación vanguardista de las culturas “exóticas,” herencia que el escritor mexicano Fernando del Paso recoge y a la vez cuestiona en su versión novelística de la intervención francesa, Noticias del Imperio(1987). ${ }^{1}$ En varias entrevistas,

${ }^{1}$ Como es bien sabido, André Bretón definió a México como la tierra predilecta del surrealismo; una visión mitificada del país también figura prominentemente en la obra (y vida) de varios surrealistas, 
Del Paso ha comentado que considera la ocupación decididamente desde la perspectiva de los colonizados y que independientemente del grado de ambivalencia personal que sienta hacia Maximiliano, en última instancia éste debe asumir la responsabilidad por su parte en la tragedia: "yo no soy imparcial en la novela [...]. Soy definitivamente mexicano y herido y con mente de colonizado. Soy así y ésa es la responsabilidad que he asumido" (“Nuevas conversaciones” 32). ${ }^{2}$ Por consiguiente, en ésta, su novela más explícitamente histórica, el motivo de la colección puede ser leído simultáneamente como una alegoría del imperialismo y como una reevaluación de las fuerzas sociales imperiales y de la herencia problemática de otros modelos estéticos de la modernidad.

En las culturas occidentales, el coleccionismo ha sido históricamente una estrategia para desplegar un individualismo posesivo mediante la cual la relación “apropiada” con los objetos de la colección contrasta con la relación "salvaje” o desviada de su contexto original (Clifford 261). De esta manera apropiarse del Otro es también adueñarse de su significado, aunque se falsifique la noción del proceso histórico en la medida en que al sustituir la narrativa de la producción con la de la colección, las fuerzas históricas son reemplazadas con el mito del sujeto individual. Con el auge del discurso científico en los siglos XVIII y XIX, estas colecciones se extienden a todo lo que parezca exótico: la flora, la fauna e incluso los seres humanos son clasificados y organizados por los científicos europeos encargados de explorar los recursos naturales para una potencial explotación imperialista. Esta práctica de coleccionar culturas es inseparable de una percepción del mundo material en la que se atribuye un valor desmesurado a la acumulación de posesiones y que tal acumulación es en sí parte de una “demarcación de un dominio subjetivo que no es lo 'otro"” (Clifford 260). Al mismo tiempo, sin embargo, como ha señalado Edward Said, ni el imperialismo ni el colonialismo se limitan al acto de acumulación y adquisición, ya que ambos se apoyan y hasta se impulsan por formaciones ideológicas que "incluyen nociones de que ciertos territorios y pueblos requieren y suplican ser dominados” (9). Al escribir durante los primeros años de la intervención, Brantz Mayer describe a los mexicanos en términos especialmente paternalistas:

Los hombres descuidados, indolentes y holgazanes; las mujeres sucias, rodeadas por una colección de diablillos pequeñitos y desnudos, tan sucios como sus padres; y todos gateando y revolcándose en la inmundicia [...] un puñado de maíz, una penca de plátanos, o un platillo de frijoles que han recogido de los matorrales cercanos es su comida diaria, y así se cobijan en una madriguera como animales, desde su juventud hasta [...] la tumba [...]. ¿Se espera que hombres así puedan gobernarse a sí mismos? ¡A una población así-

entre otros, Antonin Artaud, Georges Bataille, Roger Caillois y Benjamín Péret. Para Del Paso, su novela presenta el mundo al revés: "son los mexicanos, representados por Benito Juárez, los que tienen los pies en la tierra, los que entienden mejor la realidad.... En cambio los europeos, representados en la novela principalmente por Maximiliano y la locura de la aventura imperial, representan un mundo exótico y fantástico. El exotismo está en Europa y la realidad en América Latina” (“Un novelista por la totalidad" 48).

${ }^{2}$ En otra entrevista Del Paso comenta: "Yo le echo en cara a Maximiliano toda la sangre derramada de los miles y miles de mexicanos que los franceses mataron aquí. Tal vez los franceses habrían traído otro, pero Maximiliano aceptó, y fue cómplice de todas esas muertes. Él vino como un usurpador” (“Ecos del Imperio" 9). 
-pobre y servil—poco le importa la política, y sería un acto de caridad gobernarlos sabia y justamente! (cit. Massey 16-17).

Los comentarios despectivos de Mayer no son necesariamente representativos de todos los testimonios europeos. Debemos notar, además, que descripciones de la clase obrera en Europa durante esa época también solían usar términos como "animales," "salvajes” y "bárbaros” (Harvey 161, 183). Sin embargo, su planteamiento final, que describe a los indígenas como primitivos que necesitan la protección europea, es reiterado continuamente, aun por los monárquicos mexicanos. Desde los primeros encuentros con el Nuevo Mundo, la percepción mayoritaria en Europa de los nativos dictaminaba que fuesen considerados objetos de consumo personal, actitud que siguió vigente en el discurso científico más allá del siglo XIX, no obstante la intervención de la retórica romántica del buen salvaje. Como esclavo o como obsequio, el nativo es "muy literalmente capturado por y para la representación europea” (Greenblatt 119). Y de hecho, las exhibiciones de indígenas siguieron siendo muy populares en Europa durante todo el siglo XIX. $^{3}$

La mercantilización del Otro se sugiere en la novela de Del Paso mediante la obsesión de Maximiliano por clasificar plantas y animales del Nuevo Mundo y, en particular, por su fascinación con la vida de los insectos. En este aspecto, el novelista mexicano no se ha desviado mucho de sus fuentes. Centule de Béarn, agregado de la embajada francesa, describe a Maximiliano deambulando por los campos de Cuernavaca en "una bata sucia” cazando mariposas e insectos, retrato secundado por el secretario personal del archiduque y repetido frecuentemente tanto en las representaciones históricas como en las literarias e incluso en las cinematográficas (Castelot 69-70, Blasio 115). Además, una de las expediciones más importantes antes de la invasión había sido la de la Misión Científica Francesa a México y América Central, en la que tuvo un papel prominente el entomólogo francés Henri de Saussure (Soler Frost 49). En la novela, Del Paso le da un giro irónico a la descripción histórica al presentar a Maximiliano poco antes de su muerte clasificando una chinche en su celda a la que apoda Cimex domesticus Queretari. El archiduque mordazmente asocia al insecto con sus captores republicanos, por ser "un animalito que disfruta muy en particular de la sangre azul,” comparación que llega a ser aun más notable al determinar que el insecto en cuestión no puede estar en su celda (521-22). ${ }^{4}$ Irónicamente, su plan de disecar la chinche y enviarla a Europa prefigura su propio destino final, paralelo que se subraya cuando intenta localizar al animalito con un espejo. De hecho, se podría llegar a postular que el parásito en la celda es el mismo Maximiliano, cuyo intento de asumir el papel de mandatario legítimo no es tan distinto del camuflaje de un insecto que

\footnotetext{
${ }^{3}$ El modelo del discurso científico también mediatizó la narrativa criolla. Quizás el ejemplo más conocido sea el de Domingo Sarmiento, que en Facundo analiza al gaucho como si fuera otro animal para ser clasificado.

${ }^{4}$ Increíblemente, este episodio también se basa en los hechos históricos, ya que Maximiliano le escribió a su amigo Billineck durante el sitio de Querétaro (no sin ironía) sobre "una nueva especie de chinche [...] que parece tener las mandíbulas dobles y que sorprende a todo el mundo. Si yo hubiese podido traer unos frascos, habría, pese a la preocupación de la guerra, conservado algunos ejemplares para mostrárselos” (Castelot 396).
} 
adopta las características físicas de su ambiente. Puesto que los cuerpos de los insectos cumplen naturalmente esta función, podemos aseverar que, de alguna manera, éstos son los cómplices astutos por excelencia (Burstein 156). Esta facultad mimética es relevante para una discusión del poder colonial ya que, como observa Homi Bhabha, la mímesis es una de las “estrategias más eficaces y más elusivas del poder y conocimiento coloniales” (126). Lo irónico es que al mismo tiempo que Maximiliano trata de convencer a sus presuntos súbditos de su "mexicanidad"-vistiéndose de charro, recreando el grito de independencia en Dolores Hidalgo — también se esfuerza por imitar a Napoleón III al imponer todos los símbolos y el ceremonial de la realeza. Aparte del voluminoso Ceremonial de la corte al que Del Paso se refiere con frecuencia, los proyectos principales de Maximiliano durante su estancia en México se destacan por su insustancialidad: construyó un teatro nacional, amplió el paseo de Chapultepec hasta el Palacio Nacional al estilo de los Champs Elysées parisinos, y deslumbró, aunque momentáneamente, a los mexicanos de la élite con sus suntuosos banquetes y bailes. Mas no había nada sustantivo debajo de la pompa y circunstancia: en la novela, hasta las flores en las fuentes imperiales son artificiales (326). ${ }^{5}$ Stephen Greenblatt ha denominado la disposición europea a seguir ciertos modelos de intercambio comunicativo la “mímesis apropiativa,” una repetición de gestos que no indica necesariamente una comprehensión de la realidad cultural del Otro (99). Tales representaciones, así como los ritos falsos y la retórica democrática sobre los que se basa el imperio de Maximiliano, enmascaran las verdaderas e insidiosas intenciones del imperio.

Los esquemas clasificatorios mediante los cuales los naturalistas buscaban “naturalizar” la presencia global de Europa occidental coinciden con la estrategia de representación que Mary Louise Pratt ha denominado la “anti-conquista," fundamentada, precisamente, en las "aspiraciones continentales y transnacionales de la ciencia europea,” y ejemplificada por el sistema de Linneo para la clasificación de la naturaleza aplicado con "fervor mesiánico" a partir de las últimas décadas del siglo xviII (28). Como sugiere Pratt, la "reinvención” de Hispanoamérica durante el siglo XIX continúa muchos aspectos de estos proyectos anteriores en la medida en que categoriza a las Américas como un mundo primordialmente natural que necesita la intervención europea para organizar su sociedad y su economía. De la misma forma en que se clasifican las plantas, los animales y los insectos, las poblaciones no-europeas regularmente son codificadas en grupos por el discurso científico, llegando este modelo a mediatizar hasta las narraciones históricas. Los testimonios que tratan el período de la intervención francesa en México casi siempre incluyen un capítulo explicatorio sobre la raza. En esta representación esencialmente fetichista, los pueblos indígenas son a menudo idealizados o evocados de manera paternalista, reservándose la crítica más dura para los mestizos, a quienes se les describe como perezosos, arrogantes y de poca confianza. ${ }^{6}$ El príncipe austríaco Carl Khevenhüller desdeña la soberbia de los mestizos que "se creen blancos," aunque en realidad, según él, "heredaron todos los

${ }^{5}$ De hecho, el motivo del disfraz y la máscara aparece a lo largo de la novela. Sobre este aspecto, véase mi artículo "Sueños imperiales: La teatralidad en Noticias del imperio."

${ }^{6}$ La figura que rompe todos los esquemas simplistas es Benito Juárez, presidente legítimo e indio zapoteca. Aunque no es inusual que lo evoquen como sanguinario o bestial (véase, por ejemplo, Felix Salm-Salm 298; A.C. 84 ), lo más común es que Juárez inspire respeto tanto para los europeos 
defectos de las dos razas, sin poseer ninguna de sus buenas cualidades” (Hamann 114, traducción corregida). El francés Charles de Bouzet se muestra todavía más severo, al sostener que la sociedad “semi-bárbara” de México es tan “degenerada” que sería imposible redimirla $(18,26)$. Retórica de esta índole es frecuente en el siglo xIx y no debe sorprendernos que se haya utilizado con fines políticos. Como observa Pratt, esta crítica, que necesariamente se extiende a los criollos, tiene también móviles económicos, ya que a través de tales representaciones estereotipadas los autores imperialistas pueden afirmar que los descendientes de los españoles no han sabido explotar los recursos naturales del país (150). Al categorizar a una cultura entera como extensión de la naturaleza indómita, la intervención se autodefine como un gesto magnánimo de las naciones "civilizadas" hacia aquellas que supuestamente siguen en un estado de desorden y barbarie. ${ }^{7}$

Que las colecciones de Maximiliano en la novela no se limitan a plantas e insectos queda indicado claramente en la narración del marido de la amante mexicana del archiduque, Concepción Sedano. ${ }^{8}$ La naturaleza, sea pasiva o devoradora, frecuentemente es codificada como femenina: algo para controlar y conquistar, explotar y penetrar. Concepción es continuamente descrita por su esposo como una flor arrancada de su jardín $(436,437)^{9}$ y su seducción por Maximiliano es una metáfora de la violación de México por las fuerzas invasoras de Europa, invasión que se apoya en la imposición del lenguaje. ${ }^{10} \mathrm{El}$ jardinero/narrador ha aprendido todos los nombres de las flores y los árboles de su abuelo, y conoce tres, cuatro e incluso diez palabras para cada planta $(437,440)$. En contraste, los

(Maximiliano incluido) como para los mexicanos. Véanse, por ejemplo, los comentarios de un oficial francés en 1866: "Juárez no es el hombre que tanto se ha querido desacreditar en Francia; es mexicano y tiene muchos de los defectos de su raza, es cierto; pero pocos de sus compatriotas tienen tantas cualidades. Es desinteresado, pronto a retirarse si el interés de su país se lo manda, y lo que menos tiene es ser sanguinario" (Bressomet, cit. Zárate 211-12).

${ }^{7} \mathrm{Al}$ mismo tiempo — y obviamente así es en el caso de Bouzet— el referirse a la irremediable "barbarie" de los mexicanos resultó ser una observación retrospectiva muy conveniente para explicar el fracaso de la expedición francesa. Debemos agregar que los autores franceses casi unánimamente tienden a retratar a Maximiliano como un imbécil, precisamente por este motivo. ${ }^{8}$ Del Paso dice haber escrito este episodio “para hacer un ejercicio poético del abuso del poder” (“Un novelista por la totalidad" 40).

${ }^{9}$ Por supuesto Del Paso también alude al lugar común de la época victoriana que comparaba a las mujeres con flores y al hogar con un jardín, una metáfora de la interioridad que se relaciona con la miniatura. En el Diccionario de botánica cristiana (1851) Gaston Bachelard encuentra la siguiente descripción, que también se refiere a una noción bucólica de las Américas: "Esas flores creadas en cunas de algodón, son pequeñas, delicadas, color de rosa y blancas.... Esas mujercitas son muy importantes; $y$ aquellas que hablan con tono más humilde son bastante autoritarias en su hogar. Las cuatro semillas desnudas permanecen en el fondo del cáliz y se alzan en él, lo mismo que en las Indias los niños se mecen en su hamaca” (cit. Bachelard, 189-90).

${ }^{10}$ En su estudio de 1883, "La botánica entre los nahuas,” el historiador Francisco del Paso y Troncoso afirma que la taxonomía indígena no sólo es comparable al sistema de Linneo sino en cierta forma "más consecuente," ya que su nomenclatura estaba inextricablemente arraigada en la función de las plantas y sus propiedades (ya fueran rituales, medicinales o alimenticias), mientras que el sistema europeo se interesaba en la clasificación en sí, en un discurso de posesión que frecuentemente agregaba el nombre del "descubridor” al objeto en cuestión (156). Véase también Lévi-Strauss, 4344. 
científicos que han irrumpido en su jardín tienen nombres distintos para todo, no los nombres españoles, ni tampoco los indígenas, sino nombres en latín, a veces ideados por ellos mismos, como el nombre absurdo que Maximiliano le da a la chinche en su celda (439). Como había reconocido Antonio de Nebrija en la primera gramática castellana, publicada el mismo año del primer viaje de Colón, el lenguaje es siempre compañero del imperio, y así el tomar posesión representa el ejercicio de una serie de actos lingüísticos inseparables del acto de nombrar (Greenblatt 54-57). ${ }^{11}$ Maximiliano, por cierto, está preguntándole al jardinero los nombres de las flores cuando se fija en Concepción y quiere saber también su nombre: "Don Maximiliano [...] me siguió preguntando los nombres de muchas otras flores, que yo le fui dando hasta que de repente se volteó a verla [a Concepción] [...]. Don Maximiliano le preguntó entonces: y tú, tú cómo te llamas, y antes de que ella contestara, yo me puse de pie y le dije [...] Concepción Sedano, Señor, es mi mujer, y hasta estuve tentado de ponerme el sombrero como para decirle que de esa flor que era Concepción, flor de todas las flores, yo era el Señor” (440). Por si la correspondencia no quedara suficientemente clara, Del Paso subraya el significado más profundo de esta pequeña “conquista” al presentar al archiduque en Cuernavaca imaginándose ser Hernán Cortés a la espera de la llegada de la Malinche (434).

Concepción es como una mariposa capturada en la red de Maximiliano, imagen que Carlota asocia con el disfraz y el desengaño: “Dime, Maximiliano: ¿has visto a la mentira, a la maldita mentira disfrazarse con una cáscara de sueños [...]? La mentira es Concepción Sedano y tu amor por ella. Mírala, Maximiliano: es una mentira perfumada y lisa [...] alada y negra como una mariposa de la noche. Anda, vete a Cuernavaca y con tu red de mariposas, trata, Maximiliano, de apresarla, de clavar a la mentira con un alfiler [...] y cortarle las alas” (407). Las siniestras insinuaciones del episodio se evidencian aún más por las secciones que lo enmarcan. La narración del jardinero es precedida por un diálogo entre Maximiliano y su secretario, Blasio, en el que el archiduque se jacta de las expediciones de caza que ha emprendido por todo el mundo como parte de la misión "civilizadora” de las familias reales: “[H]e cazado venados y conejos en Compiègne, becafigos en Argelia, jabalíes en Gödöllö, osos en Albania, tigrillos en Mato Grosso. ¿Y sabes por qué? [...] Porque un príncipe tiene que velar por la belleza y la tradición, por la elegancia” (430). Inmediatamente después del episodio con Concepción, y en una escena claramente paralela a las afirmaciones del archiduque, Napoleón III conversa con Eugenia y su madre sobre la conducta de Carlota y la retirada de las tropas francesas de México mientras juegan a la "Lotería Instructiva de los Animales Exóticos”. Durante el juego, el emperador francés entrelaza en su mente los nombres de animales exóticos del llamado tercer mundo con eventos importantes de la historia del bonapartismo y, en particular, de la expansión territorial: el dieciocho de Brumario, Austerlitz, Wagram,

\footnotetext{
${ }^{11}$ Así cuando Colón "descubrió” América, su primer acto fue dar nombre a cada lugar, a pesar de que estaba perfectamente consciente de que ya tenían nombres indígenas: “a la primera [isla] que yo hallé puse nombre San Salvador... los indios la llaman Guanahaní. A la segunda puse nombre la isla Santa María de Concepción, a la tercera, Fernandina, a la cuarta la Isabela, a la quinta la isla Juana y así a cada una [un] nombre nuevo” (140). Del Paso alude a esto humorísticamente cuando el narrador de "La ciudad y los pregones,”un mendigo ciego, se pregunta: “¿Será que tendré que pedirles limosna en francés, que decir pardiú en lugar de Por Dios?” (165).
} 
Marengo, Magenta, Solferino, Puebla, Oaxaca, Kabilia (447). Más adelante, hablan de la Exposición Universal, en la cual, como declara Eugenia, serán exhibidas todas las maravillas (y las materias primas, agrega su marido orgullosamente) de las colonias francesas (458). Así, la idea de jugar, coleccionar y atrapar se asocia con el imperialismo. ${ }^{12}$ De hecho, en la misma conversación en que Maximiliano recuerda sus hazañas de cacería, también se refiere a su contribución a la Exposición Universal: una reproducción a escala del templo de Xochicalco. ${ }^{13}$

Las primeras crónicas europeas fragmentaron la realidad americana al describir (e imaginar) fenómenos del nuevo mundo con el lenguaje del viejo continente, produciendo frecuentemente como resultado estrafalarios híbridos barrocos que me atrevería a comparar con los cadáveres exquisitos surrealistas. ${ }^{14} \mathrm{Al}$ mismo tiempo, esta objetización de seres humanos (y la imagen del cuerpo minúsculo del insecto en particular) nos recuerda, acaso, la imagen del "minúsculo y quebradizo cuerpo humano" evocado por Walter Benjamin en su ensayo "El narrador," en el que se ilustra el momento en que se descubre que las convenciones románticas del siglo XIX son insuficientes para representar la realidad moderna (Para una crítica 112). ${ }^{15}$ Estos diminutos cuerpos (y su relación con el discurso) aparecen desde las primeras páginas de la novela, cuando Carlota asocia su casa imaginaria de muñecas con la voz de su conciencia: "No hay noche en que no me dedique a ordenar mi casa y mi conciencia”; y continúa describiendo en detalle cada pieza minúscula de su colección para poder enfrentarse con la experiencia traumática en México:

Sacudo las libreas de terciopelo de mis lacayos en miniatura [...]. Lavo [...] los mil platos minúsculos [...] les saco brillo a las fuentes de plata miniatura, limpio las alabarderos liliputienses, lavo las pequeñísimas uvas de los pequeñísimos racimos de cristal y te perdono que hayas hecho el amor con la mujer de un jardinero a la sombra de las buganvillas de los Jardines Borda. Después barro con una escoba del tamaño de un pulgar las alfombras del castillo del tamaño de un pañuelo, y sacudo los cuadros y vacío las escupideras de oro del tamaño de un dedal y los ceniceros minúsculos, y así como te perdono todo lo que me hiciste, perdono a todos nuestros enemigos y perdono a México [...]. Y sólo hasta entonces, con mi casa limpia y mi conciencia tranquila, me desvisto y me pongo mi camisón minúsculo y rezo mis pequeñísimas oraciones, y me acuesto en mi gran cama miniatura. (16-17)

La casa de muñecas, una casa dentro de otra, representa la doble clausura de Carlota, dentro del castillo y en su locura. Asimismo, denota un discurso que se coloca en contra del tiempo histórico y a favor de un tiempo transcendente que niega el flujo de la realidad

\footnotetext{
${ }^{12}$ Me he ocupado de este tema así como de un análisis más detallado del papel de Louis Bonaparte en "Sueños imperiales."

${ }^{13}$ El hecho de que Maximiliano haya escogido a Xochicalco como ejemplo de las grandezas imperiales es también paralelo a su seducción de Concepción, ya que este yacimiento se ubica en las afueras de Cuernavaca y su nombre en náhuatl quiere decir "casa de las flores."

${ }^{14}$ Recordemos que el cadavre exquis podía adoptar la forma de un dibujo o de un poema. La producción artística de Del Paso durante la época en que escribía la novela también incluía muchas figuras híbridas.

${ }^{15}$ Sobre la relación entre el modernismo europeo y la entomología, véase Burstein.
} 
vivida, sus “castillos en el aire” imaginativos. Por otro lado, la enumeración minuciosa de la miniatura "reduce el objeto a sus propiedades de significado, y esta reducción de dimensiones físicas da como resultado la multiplicación de las propiedades ideológicas" (Stewart 61, 66). Carlota recuerda que cuando era niña en el palacio de su abuelo, después sede del poder de Napoleón III, descubrió una colección de pisapapeles que reproducían castillos en miniatura en donde ella imaginaba que vivían: "habitantes muy pequeños, [...] mucho más pequeños que los que vivían en mi casa de muñecas [...]. Era como tener todo un mundo en mis manos” (412). Y efectivamente, como ha sugerido Claude Lévi-Strauss, la miniaturización de la realidad es una manera de imponer la autoridad sobre el Otro al reducir sus dimensiones a las de una cosa que puede ser, literal y figuradamente, "agarrada, sopesada en la mano, aprehendida de una sola mirada” ["saisie, soupesée dans la main, appréhendée d'un seul coup d'œil”] (45). Aunque las meditaciones de Carlota se den mayormente bajo el marco de la ilusión, según avanza la novela estas miniaturas llegan a estar progresivamente más vinculadas con la noción de los seres humanos como colecciones, como peones microscópicos dentro de la enormidad del dominio imperial. Napoleón III, que sí intentó tener a todo el mundo-o a una buena parte por lo menos- en sus manos, también se asocia con la miniatura, no sólo por su “Lotería” sino también cuando juega a la guerra con soldaditos de cartón mientras imagina su próxima maniobra para convencer a Maximiliano a que asuma el trono de México (289). Por su parte, Leopoldo de Bélgica, padre de Carlota y otro actor fundamental en el drama, parece interesarse más por las pulgas vestidas de charro y tehuana que por las complicaciones que el plan adquiere después del asesinato de Lincoln (278). Como observa irónicamente Octavio Paz en un ensayo temprano, al enfrentarse con el gigantismo del mundo industrializado quizás a los mexicanos "no nos ha quedado más remedio que el difícil arte de vestir pulgas” (319). Para Del Paso, la realidad en miniatura (y, cabe añadir, la historia “con minúscula”) siempre ocurre detrás, si no junto a, eventos humanos de suma trascendencia. ${ }^{16}$

Por supuesto, Benjamin no se refería a los insectos ni al colonialismo cuando evocó la fragilidad del cuerpo humano en el mundo moderno, pero sí delineó una correspondencia entre la atrofia de la experiencia moderna y la desarticulación de las conexiones al nivel discursivo: "El arte de la narración está tocando a su fin [...]. Nos está siendo retirada [...] la facultad de intercambiar experiencias" (Para una crítica 112). Al igual que muchos otros textos vanguardistas, esta pérdida se expresa en Noticias del Imperio a través del desmembramiento alegórico del cuerpo, tomando como punto de partida las grotescas circunstancias históricas que siguieron al fusilamiento de Maximiliano, cuando trozos de su corazón y de su barba fueron vendidos por el cirujano supervisor como souvenirs, un hecho al que Carlota alude frecuentemente. ${ }^{17}$ Tal disgregación apunta, además, a las fronteras del discurso histórico ya que, como observa Lévi-Strauss en una analogía

\footnotetext{
${ }^{16}$ Resulta significativo que en el pasaje en que Carlota enumera todas las piezas diminutas de su colección también se imagine a sí misma con su "camisón minúsculo" rezando sus "pequeñísimas oraciones" antes de acostarse en su "cama miniatura” (17). Para Paz, la Europa moderna quizás se ha hecho "demasiado pequeña, incapaz de contener un industrialismo voraz y estéril” (319).

${ }^{17}$ Esta leyenda fue circulada por el testimonio — no siempre confiable—del príncipe prusiano Félix Salm-Salm y su esposa norteamericana, Agnes (véase 226-27). No obstante, otros textos mencionan la venta del pelo y barbas del archiduque y todavía quedan copias de las morbosas cartes de viste
} 
especialmente apropiada, el historiador y el agente histórico “eligen, cortan, y recortan” [“choisissent, tranchent et découpent”] los hechos, seleccionando y trinchando fragmentos de la realidad como representativos de la totalidad de una cultura (372). Volvemos así a la representación parcial que suponen tanto el mimetismo colonial como las colecciones, las cuales desempeñan una función semejante al "arrancar los objetos de sus contextos específicos [...] haciendo que ellos 'representen' totalidades abstractas” para crear "la ilusión de la representación adecuada de un mundo" (Clifford 261). ${ }^{18}$

$\mathrm{Al}$ sustituir una parte del cuerpo/historia para representar la totalidad, el cuerpo entero llega a ser fetiche. El desmembramiento como metáfora del discurso fragmentario y mimético se hace particularmente evidente en la sección titulada "Camarón, Camarón." Aquí el narrador convierte la mano postiza del Capitán D’Anjou en mercancía al reproducir y vender copias de la mano y de la historia que la circunda, porque el souvenir no tiene sentido sin una narración explicatoria que lo complete: "Y aquí les traigo, señores. Y si les dicen, y se les cuentan por allí que he vendido más de una vez la mano del Capitán D’Anjou, es que es verdad, pero es mentira. Como no nada más de contar cosas se puede vivir [...] me puse a hacer varias manos de madera iguales a las del Capitán D’Anjou [...]. Pero ésta es la auténtica mano [...]. La tengo certificada por el propio Capitán D’Anjou que la firmó poquito antes de morir” (219-220). La correspondencia entre el discurso escrito y esta imagen es realzada, como ha señalado Cynthia Steele, por el hecho de que el objeto en cuestión sea una mano, asociado por consiguiente con el acto de escribir (85). Que el narrador reproduzca copias de una mano que era una imitación o copia en primer lugar, y después venda la historia de esa mano (insistiendo en que se trata de la mano “original” y "verdadera") pone de relieve el acto de mimetismo paródico en la narrativa de Del Paso, así como el proceso de narración evocado en el ensayo de Benjamin. En efecto, el filósofo alemán se refiere explícitamente al cambiante papel del testimonio histórico en la época de la reproducción mecánica (Discursos interrumpidos 22). ${ }^{19}$ Mientras el tono de la narración sobre la mano postiza del Capitán D’Anjou y los demás improbables recuerdos que el narrador en “Camarón, Camarón” intenta traficar (pieles de ratas, huesos de capulines, plumas de colibrís) es grotescamente cómico, la mercantilización del cuerpo humano se reitera después de una manera trágica en el episodio en que el Coronel Du Pin brutalmente tortura al mensajero nacionalista Juan Carbajal clavando exvotos de manos, piernas y corazones en su cuerpo y advirtiendo a su víctima que tiene planeado poner su sombrero en la pared con sus demás "trofeos de caza” (267). Como sugiere Steele, la postura del autor se hace patente al describir la tortura de Carbajal como una "crucifixión," siendo tampoco arbitrario que las iniciales de su nombre sean las

producidas en serie después de la ejecución. La circulación de estas tarjetas, que incluyen fotos de Maximiliano y Tomás Mejía muertos y las prendas sangrientas del archiduque, fue prohibida en Francia.

${ }^{18}$ En la versión original Clifford se refiere a un acto de “cutting out,” verbo que quizás ilustre más claramente la analogía que propongo aquí.

${ }^{19}$ Irónicamente, los franceses también alegan haber recuperado la mano, que veneran cada año en conmemoración de la batalla de Camarón. Este incidente sin duda nos recuerda las funciones igualmente fetichistas de la pierna de Santa Anna o el brazo de Álvaro Obregón, con una diferencia importante, que la mano de D’Anjou era postiza. 
mismas que las de Jesucristo (81). Por ser mensajero, Carbajal también se asocia con la palabra escrita y, específicamente, con el proyecto discursivo de Carlota, quien depende de un mensajero imaginario para que le traiga a ella (y a los lectores) noticias del otro lado de la historia. Esta correspondencia se reafirma cuando Carlota imagina al emisario, disfrazado de verdugo, clavando un alfiler en la lengua de Maximiliano por cada mentira que ha contado (353). Más tarde, Del Paso sitúa la invasión francesa de México dentro del contexto más amplio de la barbarie imperialista al referirse a los canastos llenos de manos cortadas que durante el reinado de Leopoldo II los belgas llevaban de pueblo en pueblo en el Congo para mostrar a sus súbditos el destino que les aguardaba si no se sometían al orden imperial (633).

La imagen de Du Pin perforando el cuerpo de Carbajal y usando su sombrero como trofeo de caza también nos recuerda la visión imaginaria que tiene Carlota de Maximiliano clavando a su amante Concepción Sedano junto con los demás especímenes de su colección de mariposas. Por su énfasis en el afán de poseer, Jean Baudrillard ha propuesto una analogía entre el coleccionismo y la sexualidad (98), y la noción de "clavar” tiene además connotaciones sexuales en la novela. ${ }^{20}$ En el fragmento sobre Concepción el narrador/jardinero describe el sexo femenino como una "flor secreta de la que siempre está prendida una mariposa negra con las alas abiertas” (443), mientras que Carlota relaciona a la mariposa y, concretamente, a las "mariposas negras" con la sexualidad y la fertilidad $(307,421)$. Este símbolo alude a sus poderes creativos ya que las mariposas negras pueden ser visualizadas como las letras negras en la página, de la misma forma que en el fragmento "Yo soy un hombre de letras" se refiere lúdicamente al poder de las letras como los ladrillos con los que se edifica el discurso. ${ }^{21}$ El narrador, por cierto, compara la imaginación de Carlota con una mariposa, pero aquí el flujo caótico e imaginativo de la loca representa un contrapunto irónico con la noción de virilidad desbordante en el impulso imperial: "libre, sí, libre y omnipotente aunque al mismo tiempo presa, mariposa aturdida y ciega, condenada, girando siempre alrededor de una realidad inasible que la deslumbra y que la abrasa y se le escapa” (645). ${ }^{22}$

Como señala Clifford, el uso de la yuxtaposición o collage como estrategia de representación era un recurso surrealista familiar que pretendía romper los "cuerpos" convencionales (objetos e identidades): "El cuerpo, como una cultura semióticamente imaginada, no es una totalidad continua sino un montaje de símbolos y códigos convencionales” (166-67). Carlota reconstruye el cuerpo de Maximiliano en varias

\footnotetext{
${ }^{20}$ De hecho, la tortura de Carbajal se centra principalmente en las partes del cuerpo que más se asocian con la sexualidad (las tetillas, los labios, el prepucio, los testículos, las nalgas) y el mensaje que llevaba estaba escondido en un trozo de carne. Para una discusión de las resonancias sexuales de este episodio, véase Steele.

${ }^{21}$ La mariposa negra evoca además a la deidad prehispánica, Itzpapálotl, la "mariposa de obsidiana" y voz poética en el poema surrealista de Octavio Paz con ese nombre que también asocia la sexualidad con la conquista ("la herida que no cicatriza").

${ }^{22}$ En esto quizás se halle más cerca de lo que describe Benjamin en su ensayo sobre el coleccionismo, refiriéndose al "gusto rabelaisiano por las cantidades, perceptible hasta en las exuberantes repeticiones de sus textos” (Discursos interrumpidos 119). Benjamin distingue entre la colección privada que aspira a la totalidad y la del museo que se contenta forzosamente con una representación parcial.
} 
ocasiones: como maniquí, como tres muñecos en ataúdes minúsculos y como imagen diminutiva de celuloide. "[N]adie hay en el mundo, Maximiliano, como yo, para hacerte y deshacerte,” cuenta, imaginando el cuerpo de su marido como una amalgama surrealista compuesta de pedazos de otras figuras históricas: "puedo, si quiero, pegarte con engrudo las barbas negras de Sedano y Leguizano y cortarte una pierna y ponerte la de Santa Anna, y cortarte la otra y coserte la de Uraga, y vestirte con la piel oscura de Juárez y cambalachear tus ojos azules por los ojos de Zapata para que nadie, nunca más se atreva a decir que tú [...] no serás nunca un mexicano hasta la médula de los huesos” (117). En esta síntesis imaginativa el fragmento corporal llega a tener simultáneamente otra connotación: en vez de utilizarse para reafirmar el discurso oficial, los pedazos se reconfiguran para postular una recreación radical del pasado, empresa con resonancias tanto del cadáver exquisito de los surrealistas como de la novela de Del Paso. ${ }^{23}$

Si el experimentalismo vanguardista propone que la forma literaria es una manera de tratar cuestiones del ámbito extratextual, entonces el lenguaje se convierte en un medio privilegiado para la creación de nuevas formas de percepción. Mas la ineludible historicidad de toda la obra novelística de Del Paso indica que ya no basta con diseccionar los arreglos artificiales de la cultura: hay que utilizar esta desarticulación como punto de partida para una reconsideración del discurso, y, como extensión, de la realidad imperante. ${ }^{24}$ Esta estrategia discursiva se encarna en el personaje de Carlota, voz que forma parte de la retórica imperialista por ser una figura histórica perteneciente a este orden petrificado, y, simultáneamente, al ser reinventada por la novela, portadora de una estética innovadora precisamente por su marginación de este orden. ${ }^{25}$ Mientras el cuerpo usurpado de Concepción traza un mapa de la consolidación de ciertas relaciones de poder (y, también, de la lectura decimonónica de la mujer como parte integral de la naturaleza), el cuerpo imaginado de Carlota, en contraste, representa al texto literario como anagrama erótico que desestabiliza los presupuestos culturales e históricos de los lectores a través del lenguaje. En Noticias del Imperio, el cuerpo de Carlota se expone como la página en blanco sobre la cual la tinta roja de su sangre escribirá la historia oculta detrás de la mascarada del imperio (22). En su piel, afirma, está escrita la verdadera historia, y es allí, también, donde Maximiliano, los mexicanos y "todos los que quieren entenderme" tendrán que "aprender a leer de nuevo" y descubrir lo que ella quiere decir entre líneas (492).

\footnotetext{
${ }^{23}$ Desde luego, tal empresa también se relaciona con la idea de la posmodernidad y, en particular, con la metaficción historiográfica que ha descrito Linda Hutcheon.

${ }^{24}$ Aunque la metáfora de "diseccionar" encaja bien con la discusión sobre los insectos, aquí me refiero a la famosa definición de belleza propuesta por Lautréamont, "el encuentro casual en una mesa de disección de una máquina de coser y un paraguas,” escrita durante la misma época en la que Maximiliano estaba intentando preservar a toda costa la integridad de un pasado ya en vías de descomposición. Las dos novelas anteriores de Del Paso también abarcan temas históricos: José Trigo (1966) trata la huelga ferroviaria de 1958 y Palinuro de México (1977) culmina con la matanza de Tlatelolco.

${ }^{25}$ Recordamos, asimismo, que los surrealistas franceses habían celebrado la histeria femenina como "La plus grande découverte poétique de la fin du xixe siècle” (Breton/Aragon 20).
} 
De la misma manera en que procura reinventar a su marido muerto hilando pedazos de su historia, el propósito discursivo de Carlota, y de la novela, es crear una totalidad a través de una síntesis imaginativa de las partes. El proceso de modernización, como ha sugerido Marshall Berman, hizo estallar la realidad en una multitud de fragmentos hasta tal punto que hemos "perdido el contacto" con las raíces de nuestra propia modernidad (17). Carlota dice que aunque la amarran a su cama, ella se escapa de noche para buscar los pedazos rotos de su espejo y que con estos fragmentos ella quiere hacer algo nuevo, un espejo que no cuente mentiras, en el que se pueda ver "de cuerpo entero" y donde se vislumbre la "vida entera en un instante" $(408,414)$. Si, como sugiere Del Paso, el legado del imperialismo sigue pesando en la realidad hispanoamericana de hoy en día, entonces no basta con dar una lección de historia a los lectores: hay que ayudarlos a ver los eventos del pasado con ojos nuevos. La visión del surrealista mundo interior de la loca (y ciega) Carlota constituye, entonces, un contrapunto creativo con la visión falsa de Maximiliano, representada por los ojos postizos que le ponen después de su muerte: “Si quieres saber lo que es la mentira [...] lo reconocerás por el asombro esponjoso de tus ojos postizos [...]. Los ojos no son los tuyos. Son los ojos de Santa Úrsula. Si quieres, Maximiliano, conocer la mentira, contémplate en el espejo de mis sueños, y la verás de cuerpo entero” (409). El hecho de que estos ojos se originen en la imagen de una santa apunta a la representación de Maximiliano como mártir; el que sean negros, a su "mexicanización.” Pero su condición de artificio pone de relieve la falsedad: aunque Maximiliano se disfrace de Cristo sigue siendo usurpador e impostor. Los verdaderos mártires, sugiere la novela, son los héroes olvidados como Juan Carbajal, asesinado al final, como lo fue Santa Úrsula, “con el corazón atravesado por una flecha” (Bentley 207). ${ }^{26}$ Significativamente, la última parte del cuerpo que se le perfora a Carbajal antes de morir es el párpado, hecho que acaso recuerde la importancia de la visión en los textos vanguardistas. ${ }^{27}$ No es casualidad, entonces, que la miniaturización de la realidad en el discurso de Carlota no sólo se asocie con la apropiación del otro sino que sirva también como punto de partida, explícitamente visual, para la invención de su mundo alternativo:

[B]astaba que me sentara yo sola, con las manos vacías, para que de pronto, y sostenida por ellas, se apareciera en mi regazo una esfera de cristal, y dentro de la esfera una ciudad completa [...]. Por esas calles [...] pasaba, también, la historia [...]. Me paso los días enteros sentada en mi habitación, con la cabeza inclinada y las manos en el regazo con las palmas hacia arriba. Ahora, y todos estos años en que mis carceleros han creído que no sólo mis manos están vacías sino también mi mente, si ellos pudieran nada más que ver con mis ojos, se asombrarían... de lo infinitamente grandes que son los pensamientos con los que le doy forma y sentido a un mundo y lo ilumino con auroras boreales, con relámpagos, con noches blancas. (413)

\footnotetext{
${ }^{26}$ He comparado el martirio de Carbajal con el falso martirio de Maximiliano en "Sueños imperiales”. ${ }^{27}$ En particular esta imagen me recuerda la del "párpado atrozmente levantado a la fuerza” de Pablo Neruda en "Agua sexual” de la segunda Residencia o acaso el ojo hendido en Un chien andalou de Luis Buñuel. Carlota pide poner la piel y los párpados de Maximiliano para hundirse en sus sueños en un pasaje que tiene resonancias de la mitología nahua (184). El ojo destrozado como imagen de clarividencia también aparece en la cosmogonía mexica.
} 
La imagen de las manos con las palmas abiertas, con sus resonancias iconográficas de Jesucristo, subraya la autoridad que Carlota quiere postular para su discurso, a pesar de que rechace asumir el cuerpo de mártir “con las manos estigmatizadas y los pies perforados” (416), optando en cambio por la mariposa de la resurrección, resurrección que sólo se dará por la confluencia de perspectivas que se reúnen en el lector. Porque la condena de Carlota, como ella misma dice, es también su privilegio, y su creación más subversiva: "el privilegio de los sueños y de los locos, inventar, si quiero, un inmenso castillo de palabras” (117).

Básandose en una historia alternativa de la memoria y la imaginación, la literatura sólo es fiel al lector y a la historia cuando transgrede las normas estéticas inventando formas nuevas. La función de la literatura no es reflejar la realidad sino mostrar que personajes y acciones son productos históricos y por tanto hubieran podido ser, y todavía pueden ser, distintos. El espejo de la narración de Carlota nos presenta un mundo invertido en el que se subvierten todas las categorías de la lógica especular; es, más que nada, una nueva forma de percepción y de expresión. Por ello refleja la imaginación en su capacidad infinita de emular el universo visible e invisible. Como cuerpo, como nación, como lenguaje y como novela, Carlota, al igual que Noticias del Imperio, es por cierto un cadáver exquisito. ${ }^{28}$

\section{Bibliografía}

A.C. Maximilien et la monarquie au Mexique. Paris: Amyot, 1867.

Baril, V.L. Le Mexique, résumé géographique, statistique, industriel, historique et social à lusage des personnes qui veulent avoir des notions exactes, récentes et précises sur cette contrée du nouveau-monde. Douai: Ceret-Carpentier, 1862.

Baudrillard, Jean. El sistema de los objetos. Francisco González Aramburu, trad. México: Siglo XXI, 1975.

Belenkii, Aleksander Borisovich. La intervención extranjera de 1861-1867 en México. México: Fondo de Cultura Económica, 1966.

Benjamin, Walter. Discursos interrumpidos. Jesús Aguirre, trad. Madrid: Taurus, 1973. Para una crítica de la violencia y otros ensayos. Marco Antonio Sandoval, trad. México: Premià, 1982.

Bentley, James. A Calendar of Saints: The Lives of the Principal Saints of the Christian Year. Nueva York: Facts on File, 1986.

Berman, Marshall. All That is Solid Melts into Air: The Experience of Modernity. 2da. ed. Nueva York: Penguin Books, 1988.

Betts, Raymond. The False Dawn: European Imperialism in the Nineteenth Century. Minneapolis: University of Minnesota Press, 1975.

Blasio, José Luis. Maximiliano íntimo: el Emperador Maximiliano y su corte: memorias de un secretario particular. París: Viuda de C. Bouret, 1905.

\footnotetext{
${ }^{28}$ Una versión de este ensayo fue leído en la Kentucky Foreign Language Conference, el 29 de abril del 2000. Este artículo fue posible en parte gracias a la subvención del Institute for Scholarship in the Liberal Arts de la Universidad de Notre Dame.
} 
Bouzet, Charles de. La intervención francesa en México. San Luis Potosí: Imprenta del Gobierno, 1867.

Breton, André y Louis Aragon. “Le cinquantenaire de l'hysterie”. La révolution surréaliste 11 (1928): 202-22. Rpt. La révolution surréaliste. Nueva York: Arno, 1968.

Burstein, Jessica. “Waspish Segments: Lewis, Prosthesis, Fascism”. Modernism/Modernity 4/2 (1997): 139-64.

Castelot, André. Maximiliano y Carlota: La tragedia de la ambición. México: Editores Asociados Mexicanos, 1985.

Clifford, James. Dilemas de la cultura: Antropología, literatura y arte en la perspectiva posmoderna. Carlos Reynoso, trad. Barcelona: Gedisa, 1995.

Colón, Cristóbal. Textos y documentos completos: Relaciones de viajes, cartas y memoriales. Consuelo Varela, ed. Madrid: Alianza, 1982.

Foucault, Michel. The Order of Things: An Archaeology of the Human Sciences. Nueva York: Vintage, 1994.

Greenblatt, Stephen. Marvelous Possessions: The Wonder of the New World. Chicago: University of Chicago Press, 1991.

Hamann, Brigitte, ed. Con Maximiliano en México: Del diario del príncipe Carl Khevenhüller 1864-1867. Angélica Scherp, trad. México: Fondo de Cultura Económica, 1989.

Hamon, Philippe. Expositions: Literature and Architecture in Nineteenth-Century France. Katia Sainson-Frank y Lisa Maguire, trad. Berkeley: University of California Press, 1992.

Harvey, David. Consciousness and the Urban Experience: Studies in the History and Theory of Capitalist Urbanization. Baltimore, MD: John Hopkins University Press, 1985.

Hutcheon, Linda. "Historiographic Metafiction: Parody and the Intertextuality of History”. Intertextuality and Contemporary American Fiction. Patrick O’Donnell y Robert Con Davis, eds. Baltimore: Johns Hopkins University Press, 1989. 3-34.

Ibsen, Kristine. “Sueños imperiales: La teatralidad en Noticias del Imperio". Bulletin of Hispanic Studies (Liverpool): 75 (1998): 469-80.

Lévi-Strauss, Claude. El pensamiento salvaje. Francisco González Aramburo, trad. México: Fondo de Cultura Económica, 1964.

Massey, Thomas E. Mexico as it is. Washington, DC: Intelligencer Printing Establishment, 1866.

Micard, Etienne. La France au Mexique. París: Monde Moderne, 1927.

Paso, Fernando del. "Ecos del Imperio: Una conversación con Fernando del Paso”. Con Ángeles Mastretta. Nexos 138 (1989): 5-11.

Noticias del Imperio. Madrid: Mondadori, 1987.

“Un novelista por la totalidad: Entrevista a Fernando del Paso”. Con Marco Antonio Campos.

"Nuevas conversaciones con Fernando del Paso". Con Maruja Echegoyen. Cuadernos de Marcha, 2a época, 17-18 (1983): 24-32.

y Troncoso, Francisco. La botánica entre los nahuas y otros estudios [1883]. Pilar Máynez, ed. México: SEP, 1988. 
Paz, Octavio. “El arte de vestir pulgas.” Primeras letras (1931-1943). Barcelona: Seix Barral, 1988. 318-20.

Pratt, Mary Louise. Imperial Eyes: Studies in Travel Writing and Transculturation. Nueva York: Routledge, 1992.

Said, Edward W. Culture and Imperialism. Nueva York: Vintage Books, 1993.

Salm-Salm, Agnes. Ten Years of My Life. Detroit: Belford Brothers, 1877.

Salm-Salm, Felix. My Diary in Mexico in 1867, Including the Last Days of the Emperor Maximilian; With Leaves from The Diary of the Princess Salm-Salm, etc. 2 vols. Londres: Richard Bentley, 1868.

Soler Frost, Pablo. “Alas de la leyenda: Los insectos coloniales”. Artes de México, n.s., núm. 11 (1991): 45-51.

Steele, Cynthia. Politics, Gender, and the Mexican Novel. Austin: University of Texas Press, 1993.

Stewart, Susan. On Longing: Narratives of the Miniature, the Gigantic, the Souvenir, the Collection. $2^{\text {nd }}$ ed. Durham, NC: Duke University Press, 1993.

Williams, Elizabeth A. "Art and Artifact at the Trocadero: Ars Americana and the Primitivist Revolution”. Objects and Others: Essays on Museums and Material Culture. George W. Stocking, ed. Madison: University Wisconsin Press, 1985. 14666.

Zárate, Gabriel, ed. y trad. Papeles y correspondencia de la familia imperial de Francia encontrados en las Tullerías. México: Tipografía Mexicana, 1873. 